\title{
Land suitability assessment for apple (Malus domestica) in the Republic of Korea using integrated soil and climate information, MLCM, and AHP
}

\author{
Hojung Kim*, Kyomoon Shim \\ (Department of Agricultural Environment, National Institute of Agricultural Science, Iseo-myeon, Wanju-gun, Republic of Korea)
}

\begin{abstract}
Apples (Malus domestica) are one of the major fruits cultivated in South Korea and worldwide. To both sustain the productivity of apple trees and preserve the land, a land suitability assessment has been conducted. Two methods were used to analyze land suitability, a Most-Limiting Characteristic Method (MLCM) and an Analytic Hierarchy Process (AHP) with integrated soil and climate information based on the FAO classification framework. The most-limiting characteristic analysis showed that almost all areas were classified as marginally suitable (S3) or not suitable $(\mathrm{N})$, which together accounted for $94.54 \%$ of the land in the Republic of Korea. On the contrary, AHP showed that S1 (34.1\%) and S2 (44.17\%) account for the majority of the land.

Keywords: land suitability evaluation, biophysical modeling, GIS, land use planning, multi-criteria analysis, Republic of Korea DOI: $10.25165 /$ j.ijabe. 20181102.2522
\end{abstract}

Citation: Kim H, Shim K. Land suitability assessment for apple (Malus domestica) in the Republic of Korea using integrated soil and climate information, MLCM, and AHP. Int J Agric \& Biol Eng, 2018; 11(2): 139-144.

\section{Introduction}

Land suitability assessment is the process of forecasting the land's performance for special uses ${ }^{[1-5]}$. Especially in agriculture, estimating the land's potential and the limitations on producing typical products is a major issue ${ }^{[6,7]}$. The Food and Agriculture Organization (FAO) reported that land suitability assessment was necessary for productivity and preservation ${ }^{[8-10]}$. The $\mathrm{FAO}^{[4]}$ classifies land into mainly suitable land (S) and not suitable land (N); S land is further classified into highly suitable (S1), moderately suitable (S2), and marginally suitable (S3), whereas N is further classified into currently not suitable (N1) and permanently not suitable (N2).

Various geo-environmental factors such as soils, climate, topography, erosion, flood, etc., determine the suitability of the land for various agricultural products ${ }^{[2,3]}$. In the Republic of Korea, a system for soil and environmental information, "Heuktoram", provides land suitability assessment for 64 agricultural products based on soil information, and an agricultural and future electronic climate map system built by the Rural Development Administration (RDA) provides land suitability assessment for apple, pear, peach, grape, sweet persimmon, and tangerine based on climate information ${ }^{[11,12]}$. Both services provide useful land suitability assessments based on soil and climate information. However, if the results from the two can be combined, the accuracy of the results and the efficiency of big data will be enhanced.

In this study, the land suitability assessment was conducted for apple trees in the Republic of Korea using the Most-Limiting Characteristic Method (MLCM) and an Analytic Hierarchy Process

Received date: $2017-07-26 \quad$ Accepted date: $2017-12-24$

Biographies: Kyomoon Shim, Research Scientist, research interests: agricultural and forest meteorology. Email:. kmshim@korea.kr.

*Corresponding author: Hojung Kim, Post-doc Researcher, research interests: Agricultural and forest meteorology. Address: 166 Nongsaengmyeong-ro, Iseo-myeon, Wanju-gun, 55365, The Republic of Korea. Tel: +82-63-238-2522, Fax: +82-63-238-3823, Email: hojung.kim.17@gmail.com.
(AHP) based on the FAO classification given integrated soil and climate information ${ }^{[8-10,13]}$. The FAO designed the most-limiting characteristic method for land suitability assessment ${ }^{[8]}$. This method is based on assigning the most-limiting class among all factors to each area, while the most-limiting class is the class that receives the worst grade in all characteristics in an area and represents the suitability class for a crop ${ }^{[8,14]}$. On the other hand, AHP can be efficiently used to analyze complex decisions and is particularly useful in group decision-making ${ }^{[15-17]}$. The results of AHP help to decide one reasonable measure instead of providing a perfectly correct answer. Also, the AHP can be adjusted to weight various factors and variables effectively, setting relatively higher values for more important variables or factors based on the opinion of experts in the related areas. In this study, MLCM and AHP have been used efficiently in land suitably assessments, aimed to enhance the productivity of apple orchards in South Korea and provide valuable information regarding the locations of suitable areas. In this research, researchers compared and analyzed the differences between the results obtained by MLCM and AHP, and also the results obtained using integrated soil and climate information with the results gotten only from soil or climate information.

\section{Materials and methods}

\subsection{Study areas}

This research studied the land in South Korea, which is located between latitudes $33^{\circ}-39^{\circ} \mathrm{N}$ and longitudes $124^{\circ}-130^{\circ} \mathrm{E}^{[18]}$. The land of South Korea was divided into two general regions: an eastern area of high mountains and narrow coastal plains, and a western area including broad coastal plains, river basins, and rolling hills ${ }^{[19]}$. South Korea has eight administrative districts, called "Do," and divided up the analysis into the eight different Do provinces.

\subsection{Materials and methods}

GIS was used to build a geographic database of soil and climate. For the climate database, information from 1980 to 2010 was catalogued and classified into $30 \mathrm{~m}$ grid cells. Soil 
information was constructed as a vector-based database and then converted into $30 \mathrm{~m}$ grid cells to overlap with climate information.

\subsection{Weighting factors and variables}

Weights are given according to the relative importance of factors and variables. Scores of 20,15, 10, 5, and 0 were firstly given for S1, S2, S3, N1, and N2, respectively. The analytic hierarchy process (AHP) to was adapted to weight factors like climate or soil and variables in soil or climate specifically for apple trees ${ }^{[20]}$. The AHP scale for paired comparisons is presented in Table 1. There are two variables, which are soil and climate; soil has five factors and climate has two. AHP was conducted with paired comparisons within the two variables and within the five soil factors and two climate factors.
Table 1 AHP scale for paired comparisons

\begin{tabular}{cc}
\hline Intensity of importance & Definition \\
\hline $1 / 3$ & Strong unimportance \\
$1 / 2$ & Moderate unimportance \\
1 & Equal importance \\
2 & Moderate importance \\
3 & Strong importance \\
\hline
\end{tabular}

\subsection{Score for each variable category}

In this research, the climate classifications produced by the National Institute of Horticultural and Herbal Science (NIHHS) and the soil classifications produced by the National Academy of Agricultural Science (NAAS) ${ }^{[8,11,12]}$ were adapted (Table 2).

Table 2 Classification for soil and climate information

\begin{tabular}{|c|c|c|c|c|}
\hline Variable & S1 & $\mathrm{S} 2$ & $\mathrm{~S} 3$ & N1 \\
\hline Soil & $\begin{array}{c}\text { Fluvial plains, alluvial fan, } \\
\text { valley }\end{array}$ & Dilluvium & $\begin{array}{l}\text { Hill, footslope of mountain, } \\
\text { lava plateau, corrosion area }\end{array}$ & $\begin{array}{l}\text { Fluvio-marine plains, mountain, } \\
\text { cinder cone }\end{array}$ \\
\hline Slope $/ \%$ & $0-7$ & $7-15$ & $15-30$ & $>30$ \\
\hline Soil texture & Sandy loam, silt sandy loam & Clay loam & Silt clay loam, clay & Sand, gravelly soil, gravellly sand \\
\hline Drainage classes & Well & Well but too excessive & Moderately well & Poor \\
\hline Temperature during growing season $/{ }^{\circ} \mathrm{C}$ & $15 \leq x<18$ & $14.4 \leq<x<15,18 \leq x<18.7$ & $13.5 \leq x<14.4,18.7 \leq x<19.5$ & $\mathrm{x}<13.5, \mathrm{x} \leq 19.5$ \\
\hline Mean annual temperature $/{ }^{\circ} \mathrm{C}$ & $8 \leq x<11$ & $7.2 \leq x<8,11 \leq x<12.5$ & $6.5 \leq x<7.2,12.5 \leq x<14$ & $x \leq 6.5, x>14$ \\
\hline
\end{tabular}

\section{Results and discussion}

\subsection{AHP results for weights}

The AHP results for all factors and variables concerning soil and climate in consultation with experts in soil and climate conditions suitable for apple trees are shown in Table 3. Several different methodologies that have been used to give weight to factors or variables were found. Boonyanuphap et al. ${ }^{[20]}$ set weights based on literature research, and Elsheikh ${ }^{[2]}$ gave weights according to the variations of function. The results by Elsheikh ${ }^{[2]}$ showed that higher weights should be given for soil factors than for climatic factors. On the contrary, Boonyanuphap et al. ${ }^{[20]}$ determined that climatic factors should be weighted more than soil factors. AHP results in our research showed that climatic factors should be weighted more than soil factors, which is in agreement with that of Boonyanuphap et al. ${ }^{[20]}$. One possible reason for the higher weight of climatic factors seems to stem from the fact that in South Korea climatic conditions have higher variation than soil conditions, so that unusual climatic conditions can have a greater influence on the productivity of apple trees. Also, experts think that bad soil conditions can be overcome relatively easily by soil management strategies.

Table 3 AHP results

\begin{tabular}{cccc}
\hline Main factor & Weight & \multicolumn{1}{c}{ Variable } & Weight \\
\hline & & Soil morphology & 0.204 \\
Soil and & Slope & 0.121 \\
$\begin{array}{c}\text { topographic } \\
\text { factor }\end{array}$ & 0.386 & Soil texture & 0.194 \\
& & Drainage class & 0.279 \\
& & Available soil depth & 0.202 \\
\hline \multirow{2}{*}{ Climate factor } & 0.614 & Temperature during growing season & 0.614 \\
& & Mean annual temperature & 0.386 \\
\hline
\end{tabular}

\subsection{The results given by the MLCM}

Classification of land suitable for apple trees was firstly conducted using the most-limiting characteristic method (Figure 1,
Table 4). However, it is hard to easily present which areas are more suitable for cultivating apples in Figure 1. The results show that $76.44 \%$ of the land is classified as N1, which is much larger than the proportion taken by other classifications; also, S3 accounts for $18.10 \%$ of the land. N1 and S3 together account for $94.54 \%$, which is the majority of the land in the country. N2, S2, and S1 occupy $3.34 \%, 1.87 \%$, and $0.24 \%$, respectively, which are very small areas.

The whole number of cells for each grade in all areas of South Korea was also calculated (Figure 2). In each area, N1 areas were dominated, and relatively limited amounts of S1, S2, and N2 land were present, especially in Gyeongsangbuk-do and Gangwon-do. There was a large amount of variation according to area. S3 land was found in about $2 \times 10^{6}$ to $4 \times 10^{6}$ grid cells in each region, and its prevalence did not vary much.

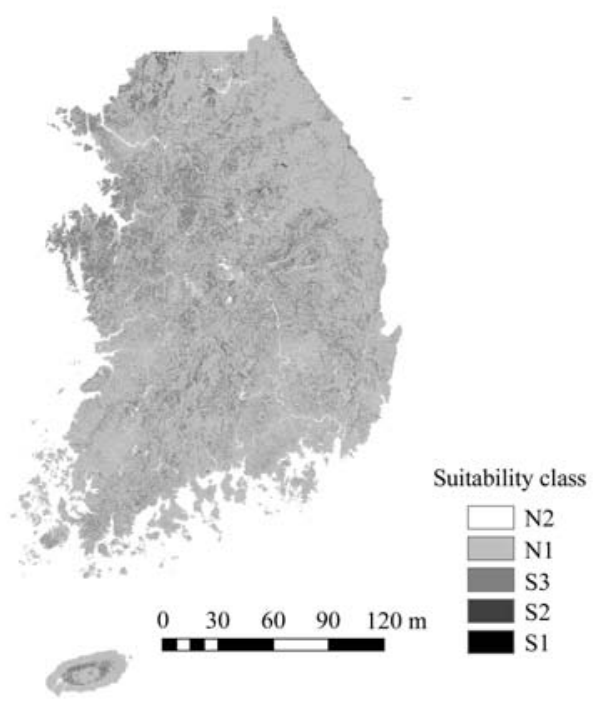

Note: N2: Permanently not suitable, N1: Currently not suitable, S3: Marginally suitable, S2: Moderately suitable, S1: Highly suitable. The same below.

Figure 1 Land suitability classification for apple trees using the most-limiting characteristic method 
Table 4 Classification results using the most-limiting characteristic method

\begin{tabular}{cc}
\hline Classification & Percentage \\
\hline N2 & 3.34 \\
N1 & 76.44 \\
S3 & 18.10 \\
S2 & 1.87 \\
S1 & 0.24 \\
Sum & 100.00 \\
\hline
\end{tabular}

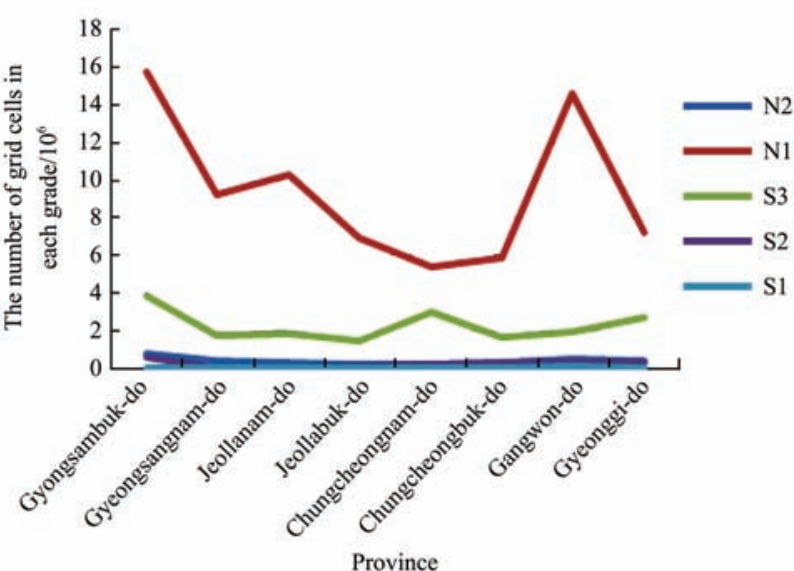

Figure 2 The number of grid cells in each grade in each according to the most-limiting characteristic method

\subsection{The results given by AHP}

Using AHP, a suitability class map based just on soil information and the percentage of land in each class are firstly presented (Figure 3 and Figure 5). S2 occupies most of the land, $60.62 \%$, and S1 and S3 occupy $10.03 \%$ and $25.43 \%$, respectively. $\mathrm{N}(\mathrm{N} 1$ or N2) only accounts for $3.92 \%$ of the land.

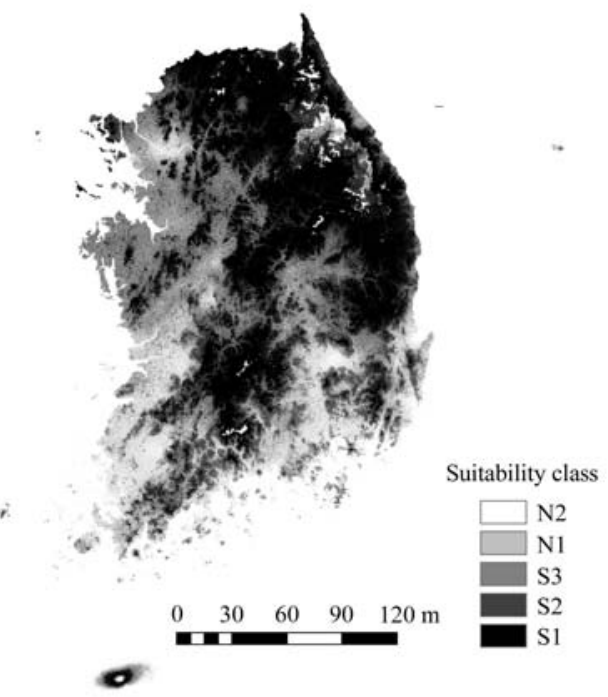

Figure 3 Suitability class map based on soil information using AHP

Table 5 Classification results based on soil information

\begin{tabular}{cc}
\hline Classification & Percentage $/ \%$ \\
\hline N & 3.92 \\
S3 & 25.43 \\
S2 & 60.62 \\
S1 & 10.03 \\
Sum & 100.00 \\
\hline
\end{tabular}

The proportion of each class in all selected areas is presented (Figure 4). The overall ranks shown in Figure 4 are consistent in all areas, and S2 dominates in all areas, especially in Gyongsambuk-do and Gangwon-do. S3 ranks second in all areas, and is relatively high in Gyeongsangbuk-do, Jeollanam-do, and Gangwon-do. S1, N1, and N2 occupy less than $2 \times 10^{6}$ grid cells in all areas.

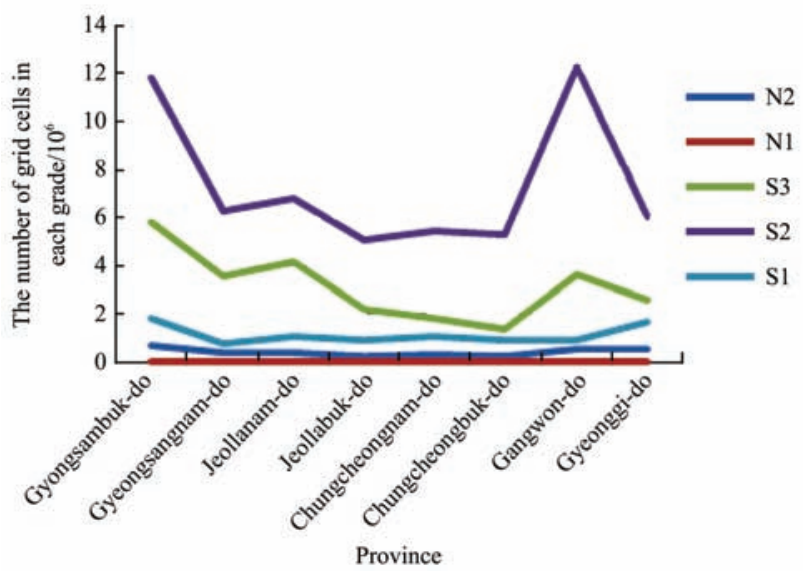

Figure 4 The number of grid cells in each grade in each area using AHP based on soil information

Among the weight values assigned to soil factors, only the weight values of drainage class and slope are not close to 0.2 ; the other values are very close to 0.2 , which is the value that would be given to each factor if no more or less weight were assigned (i.e., if all were weighted evenly). Experts who took part in the AHP research considered drainage class as a very important soil factor, but its slope is less than that of other factors for growing apples. In Kangwon-do and Gyeongsangbuk-do, soil texture values and drainage class values are very high, which seems to make the proportion of S2 land higher in other areas. The drainage class values in particular, which are assigned a relatively high weight in Table 2, potentially influence the high proportion of S2 land. In those areas, the value of the slope was not ideal but the weight of the slope was relatively low, so it is not likely to have much influence.

The suitability class map and classification results based on the climate information using AHP are presented in Figure 5 and Table 6. The climatic conditions for apples in South Korea are relatively

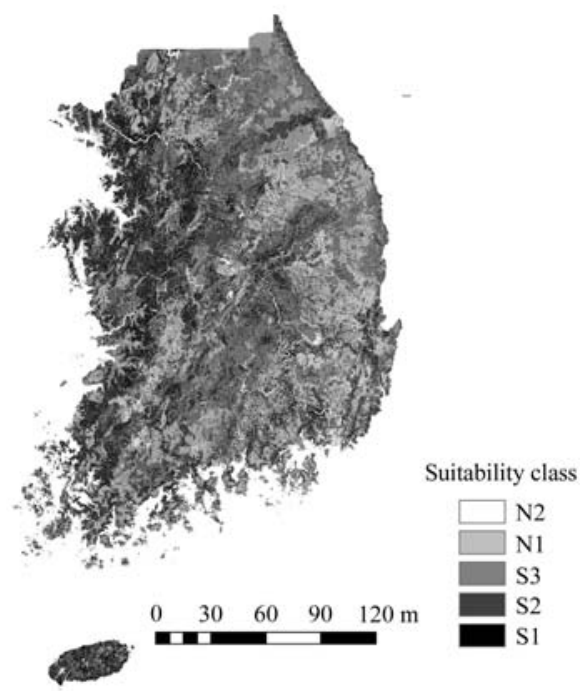

Figure 5 Suitability class map based on climate information using AHP 
good, as S1 areas occupy $40.05 \%$ of the land and S2 take up another $33.89 \%$. Together they account for $73.94 \%$ of the land. Compared with the soil information, the climate information indicates that more areas are S1 and fewer are S2.

Table 6 Classification results using AHP based on climate information

\begin{tabular}{cc}
\hline Classification & Percentage \\
\hline N & 5.07 \\
S3 & 20.99 \\
S2 & 33.89 \\
S1 & 40.05 \\
Sum & 100.00 \\
\hline
\end{tabular}

The proportion of land in each class in each part of South Korea as determined using AHP based on climate information is presented in Figure 6. S1 is especially dominant in Gangwon-do, and it is relatively high in Gyeongsanbuk-do, which seem to be quite suitable for apple trees in terms of climate conditions. Meanwhile, in Gangwon-do, S2 takes up relatively less of the land than in Gyeongsangbuk-do. In both Jeollabuk-do and Gyeongsangnam-do, S3 accounts for more land than other classes, and these seem to be less suitable areas for apple growing.

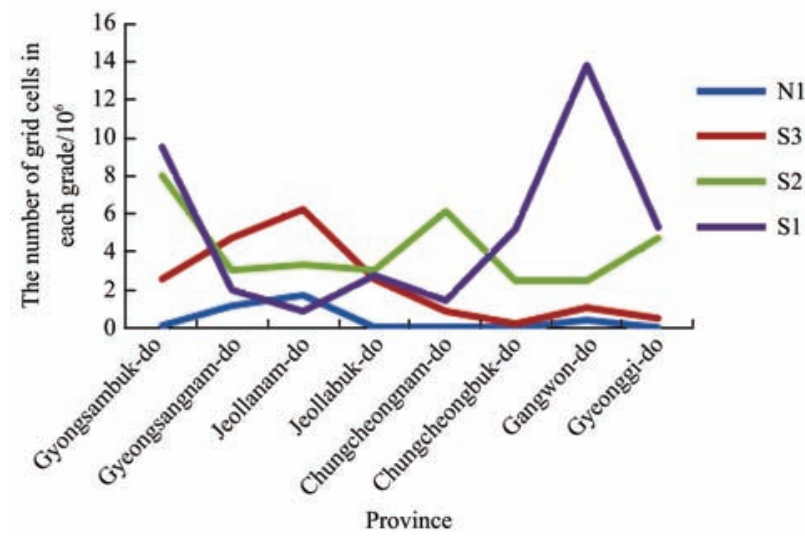

Figure 6 The number of grid cells in each grade by province as assessed using AHP based on climate information

One thing to note is that, although the proportion of S1, S2, S3, and $\mathrm{N} 1$ as determined from the soil information is consistent across all areas, the rankings based on climate information differ from each other in most areas. This seems to indicate that the temperature during the growing season $\left({ }^{\circ} \mathrm{C}\right)$ and the mean annual temperature $\left({ }^{\circ} \mathrm{C}\right)$ differ greatly across the areas, while soil structures are relatively consistent through all areas. Such results indicate the fact that the climatic environment is different and unusual climate conditions can occur in each area, and such factors seem to influence the results of land suitability assessment. This makes the higher weights assigned to climate factors than to soil factors by AHP reasonable.

A suitability class map and classification results based on climate and soil information using AHP are given in Figure 7 and Table 7. S1 occupies $34.19 \%$ of the land and S2 occupies $44.17 \%$, together they account for $78.36 \%$ of the total land. This is much greater than indicated by MLCM.

The number of areas in each class in each province as determined using AHP based on the soil and climate information in South Korea is presented in Figure 8. In Gangwon-do, S1 occupies a very high amount of the land, and in Gyeongsangbuk-do S1 and S2 account for relatively high amounts. Peculiarly, in
Jeollanam-do, most land was ranked S3 and the amount ranked S1 was extremely low.

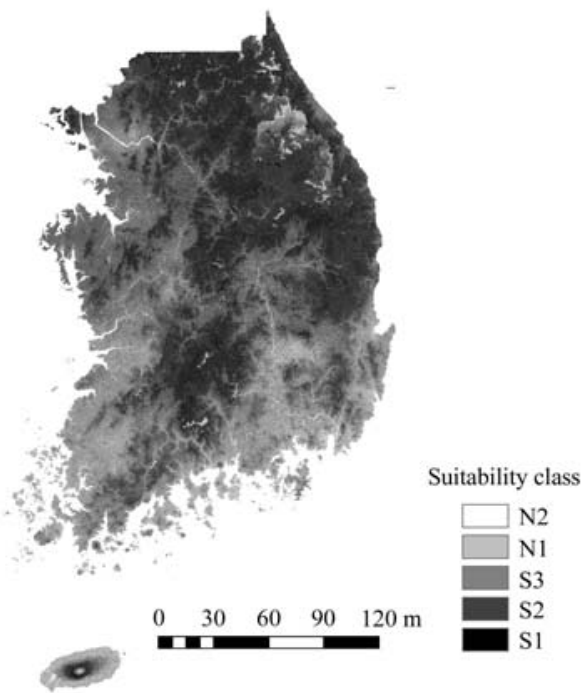

Figure 7 Suitability class map based on climate and soil information using AHP

Table 7 Classification results using AHP based on soil and climate information

\begin{tabular}{cc}
\hline Classification & Percentage \\
\hline N1 & 0.76 \\
S3 & 20.78 \\
S2 & 44.17 \\
S1 & 34.29 \\
Sum & 100.00 \\
\hline
\end{tabular}

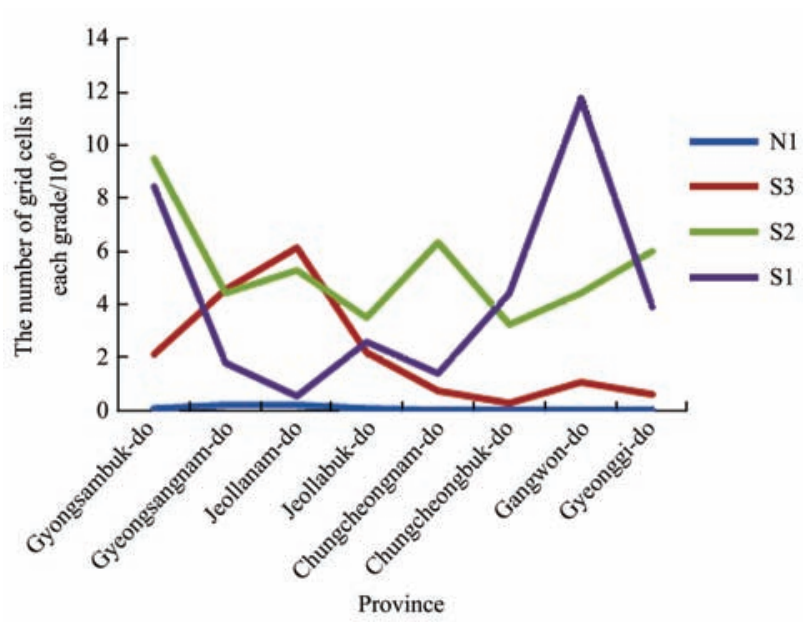

Figure 8 The number of grid cells given each grade by province using AHP based on soil and climate information

Overall, the values of each grade are very similar to the results given only the climate information. One possible reason for that is the higher weight given to climatic factors, which leads to relative consistency in the results even when soil information is taken into account.

Mean annual temperature and percentages of suitable areas $(\mathrm{S} 1+\mathrm{S} 2+\mathrm{S} 3)$ per each province by MLCM and AHP are also presented in Table 8. The results of MLCM and AHP differ greatly, and the results of AHP were much higher than those of MLCM.

One thing noted here is that in AHP N2 area was not made as any one variable among all, and this approach was considered more 
reasonable according to the AHP. However, it could be controversial for a situation when one variable is $\mathrm{N} 2$, such area could be impossible for apple cultivation, but it is not sure if any other conditions could overcome this possibility. When leaving such area as N2, the results of AHP will be lower than the current results.

Table 8 Mean annual temperature and percentages of suitable areas per each province

\begin{tabular}{lccc}
\hline \multicolumn{1}{c}{ Province } & $\begin{array}{c}\text { Mean annual } \\
\text { temperature } \\
\text { / } \mathrm{C}\end{array}$ & $\begin{array}{c}\text { \% of suitable areas } \\
\text { per each province } \\
\text { by MLCM }\end{array}$ & $\begin{array}{c}\text { \% of suitable areas } \\
\text { per each province } \\
\text { by AHP }\end{array}$ \\
\hline Gyeongsangbuk-do & 11.2 & 21.28 & 99.53 \\
Gyeongsangnam-do & 12.3 & 15.89 & 98.42 \\
Jeollanam-do & 12.8 & 15.25 & 98.40 \\
Jeollabuk-do & 11.6 & 18.06 & 99.40 \\
Chungcheongnam-do & 11.6 & 36.11 & 99.71 \\
Chungcheongbuk-do & 10.5 & 24.41 & 99.84 \\
Gangwon-do & 9.1 & 13.80 & 99.92 \\
Gyeonggi-do & 10.8 & 29.39 & 99.84 \\
\hline
\end{tabular}

\subsection{The results in Gyeongsangbuk-do and Gangwon-do}

The percentages of each grade of land in Gyeongsangbuk-do are presented according to methodology (Figure 9). MLCM indicates that $\mathrm{N}$ takes up most areas and $\mathrm{S} 3, \mathrm{~S} 2$, and $\mathrm{S} 1$ account for very little. In the results of AHP analysis given soil factors, S2 and S3 take up relatively large areas; the results of AHP given climate factors show that S1 and S2 take up more of the land. The results of AHP given integrated soil and climate factors are very similar to the results given only climate factors.

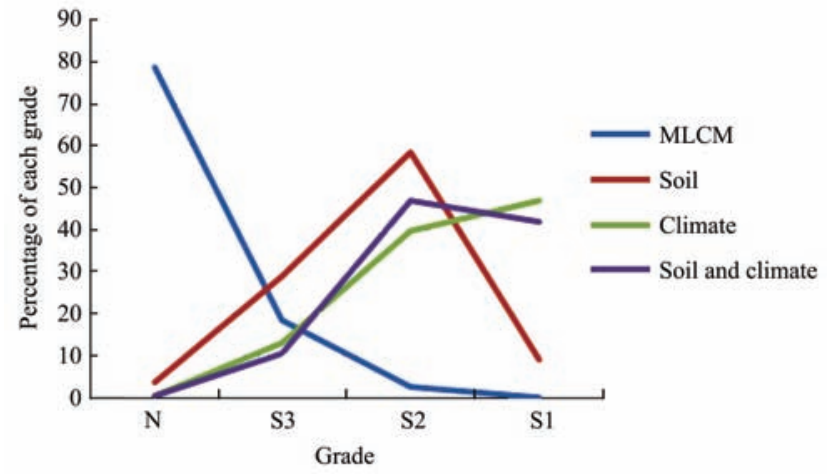

Figure 9 Percentage of each grade in Gyeongsangbuk-do according to methodology

The percentages of land in each class in Gangwon-do are presented according to methodology (Figure 10). The pattern of land grades in Gangwon-do is very similar to that of Gyeongsangbuk-do except that $\mathrm{S} 2$ is lower and $\mathrm{S} 1$ is higher.

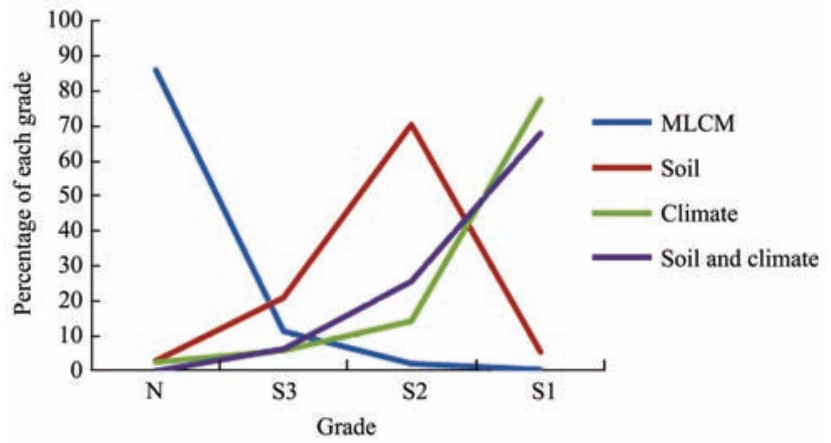

Figure 10 Percentage of each grade in Gangwon-do according to methodology
In Gyeongsangbuk-do, although the results given by MLCM were not very promising, the results given by AHP were much better, with high S2 or S1 values. In practice, Gyeongsangbuk-do held the first rank among all apple-producing areas in 2007. Results given by AHP align with the real data seems to verify the AHP methodology.

On the contrary, although Gangwon-do was ranked eighth for apple production in 2007 among all provinces, it is ranked second by the AHP methodology given soil and climate information. We can assume that as high grades, like S1 or S2, for apple trees take up more area in a district, more landowners can plant apples in that district. Based on that assumption, if the results concerning Gangwon-do generated by AHP with soil and climate information are true, it should be recommended that landowners in Gangwon-do plant more apple trees. Meanwhile, there is a possibility that the results concerning Gangwon-do given by AHP with soil and climate information are not correct. In that case it is necessary to identify where the errors came from. Moreover, the notion that a district which is highly suitable for a certain product will produce more of that product does not apply in all cases because such an area could also be very good for growing other products. So, ultimately the field data in Gangwon-do will be very useful in judging if the result of AHP analysis is credible, and this issue should be further addressed with actual field data.

\subsection{Overall discussion}

One limitation to this research is that we did not have enough published material concerning the climate and soil conditions for land suitability assessments for apple trees made by the $\mathrm{RDA}^{[2-3]}$. The RDA does not give a precise definition of each class, and the classes in soil and climate information do not seem to entirely coincide with each other. It is strongly encouraged for future authors to precisely define the meaning of each class (S1, S2, S3, $\mathrm{N} 1$, and N2) and present the details of soil and climate conditions in published work.

In particular, the rainfall conditions in the data given by the $\mathrm{RDA}^{[7]}$ do not match with real data on the amount of rainfall. The diverse climate conditions that not included could be another limitation of this research. Also, the soil data was firstly obtained as polygon data, and it was converted into raster data to better dovetail with the climate data. This conversion entailed some data loss. In addition, no reference data was provided to validate the results of the land suitability assessment, so the accuracy of the assessments cannot be judged. For future research, the assessments should be validated with real reference data.

This AHP analysis had a high consistency index (CI), 0.0183; as the CI is less than 0.1 , the results of this AHP analysis can be regarded as credible in terms of consistency. However, the experts who took part in the AHP were mostly majored in soil. If the opinions of more experts on apples or climatic conditions can be included, the results of AHP could be more well-balanced. In the next step, other methodologies for land suitability assessment could be considered.

This research makes the conclusion that the result of AHP is much higher than the results of MLCM. However, no conclusion can be made about which method is more accurate because of the lack of field data like the amount of harvest per each area. In further research, field data could be included to check the accuracy and applied in updated or mixed ways.

\section{Conclusions}

To analyze land suitability, two methods were employed, 
including MLCM and AHP with integrated soil and climate information based on the FAO classification framework.

The most-limiting characteristic analysis showed that almost all areas were classified as marginally suitable (S3) or not suitable $(\mathrm{N})$, which together accounted for $94.54 \%$ of the land in the Republic of Korea. On the contrary, a suitability class map and classification results based on climate and soil information using AHP show that S1 occupies $34.19 \%$ of the land and S2 occupies $44.17 \%$, together they account for $78.36 \%$ of the total land. Comparison of both results with real field data can be conducted in further research to enhance accuracy.

\section{Acknowledgement}

This study was carried out with the support of "Research Program for Agricultural Science \& Technology Development (Project No. PJ01000701)" National Institute of Agricultural Science, Rural Development Administration, the Republic of Korea.

\section{[References]}

[1] Sonneveld M, Hack-ten Broeke C, Van Diepen C, Boogaard H. Thirty years of systematic land evaluation in the Netherlands. Geoderma, 2010; 156(3): 84-92.

[2] Elsheikh R, Shariff A R B M, Amiri F, Ahmad N B, Balasundram S K, Soom M A M. Agriculture Land Suitability Evaluator (ALSE): A decision and planning support tool for tropical and subtropical crops. Comput Electron Agric, 2013; 93: 98-110.

[3] Bojorquez-Tapia L A, Diaz-Mondragon S, Ezcurra E. GIS based approach for participatory decision-making and land suitability assessment. Int. J. Geogr Inform Sci, 2001; 15(2): 129-151.

[4] Mahajan A, Gupta R D. Integrated Nutrient Management (INM) in a Sustainable Rice-Wheat Cropping System, Springer Science + Business Media, BV, 2009

[5] Bandyopadhyay S, Jaiswal R K, Hegde V S, Jayaraman V. Assessment of land suitability potentials for agriculture using a remote sensing and GIS based approach. International Journal of Remote Sensing, 2009; 30(4): 879-895.
[6] Zolekar R B, Bhagat V S. Multi-criteria land suitability analysis for agriculture in hilly zone: Remote sensing and GIS approach; Comp Electron Agri, 2015; 118: 300-321.

[7] Pan G, Pan J. Research in crop land suitability analysis based on GIS Comput Comput Tech Agr V, edited, Springer, 2011; pp.314-325.

[8] Food and Agriculture Organization (FAO). A framework for land evaluation. FAO Soils Bulletin 32. Food and Agriculture Organization, Rome, and publication 22. International Institute for Land Reclamation and Improvement, Wangeningen, 1976

[9] Food and Agriculture Organization (FAO). Guidelines: land evaluation for rainfed agriculture. Food and Agriculture Organization of the United Nations, Soils Bulletin 52. Rome, Italy, 1983.

[10] Food and Agriculture Organization (FAO). Land evaluation towards a revised framework. Food and Agriculture Organization of the United Nations, Rome, Italy, 2007.

[11] Rural Development Administration (RDA). Heuktoram: Soil and agricultural environments. 2010. http://soil.rda.go.kr/soil/index.jsp

[12] Rural Development Administration (RDA). U-Fruit system. 2013. http://u-fruit.nihhs.go.kr/

[13] Saaty T L. Decision making for leaders: The analytic hierarchy process for decisions in a complex world. RWS Publication, PA. 3rd Edition, 1995.

[14] Wang F. The use of artificial neural networks in a geographical information system for agricultural land-suitability assessment. Environ Plann A, 1994; 26(2): 265-284.

[15] Banai-Kashani R. A New Method for Site Suitability Analysis: The Analytic Hierarchy Process. Environmental Management, 1989; 13: 685-693.

[16] Mendoza G A. 1997. Introduction to Analytic Hierarchy process: Theory and applications to Natural Resources Management. In Proceedings of 1997 ACSM/ASPRS Annual Convention. Vol 4. Resource Technology.1997; April 7-10, Seattle, WA. pp.130-39.

[17] Saaty T L. The Analytic Hierarchy Process. New York: McGraw-Hill, 1980.

[18] Asia Info Organization (AIO). Korea's geography. 2010 http://www.asianinfo.org/asianinfo/korea/geography.htm\#LAND

[19] Saaty T L. How to make a decision: the analytic hierarchy process. Eur J Oper Res, 1990; 48(1): 9-26.

[20] Boonyanuphap J, Wattanachaiyingcharoen D, Sakurai K. GIS-based land suitability assessment for Musa (ABB group) plantation. J Appl Hort, 2004; 6(1): 3-10. 